\title{
Ergenlerde çevrimiçi oyun oynama özellikleri akran zorbalığına yol açıyor mu?
}

Do online gaming features in adolescents cause peer bullying?

\author{
Zahide Yalaki(D) Medine Ayşin Taşar (D) \\ S. B. Ankara Eğitim ve Araştırma Hastanesi, Çocuk Sağlığı ve Hastalıkları Kliniği, Ankara, Türkiye
}

Öz

Giriş: Bilgisayar oyun bağımlılığı, tüm dünyada yaygınlığı artmakta olan bir sağlık sorunudur. Ayrıca, çevrimiçi oynanan oyunların büyük kısmının şiddet içermesi diğer bir sorundur. Çalışmamızda ergen yaş grubunda bilgisayar oyun bağımlılığının akran zorbalığı ile ilişkisini araştırmayı amaçladık.

Gereç ve Yöntem: Çocuk hastalıkları polikliniğine herhangi bir nedenle başvuran 12-18 yaş arası 400 ergen çalışmaya alındı. Olgulara sosyodemografik verileri sorgulayan anket formu, çevrimiçi oyun bağımlılık ölçeği ve akran zorbalığı formu verildi.

Bulgular: Çalışma grubunun yaş ortancası 17 yıl (12-18) idi. Çalışma grubunun çevrimiçi oyun bağımlıı̆ı ölçeği puan ortalaması 52,9 $\pm 18,2$, akran zorbalığı-kurban ölçeği puan ortalaması $148,8 \pm 79,6$ ve akran zorbalığı-zorba ölçeği puan ortalaması $150 \pm 83,1$ idi. Ergenlerin \%88,4'ü çevrimiçi oyun oynadıklarını belirtti. Kızlarda çevrim içi oyun bağımlılığı ölçeği ortalaması $50 \pm 17,6$, erkeklerde ise $56,4 \pm 18,5$ idi ve erkeklerde istatistiksel olarak daha yüksek bulundu $(p=0,004)$. Çevrim içi oyun bağımlılığı ölçeği ile akran zorbalığı ölçek puan ortalaması arasında anlamlı bir ilişki saptanmadı $(p>0,05)$. Savaş içeren film seyredenlerin çevrimiçi oyun bağımlılığı ölçeği puan ortalaması daha yüksek saptandı $(p=0,001)$. Akran zorbalığı ölçeği puan ortalaması ile seyredilen film türü arasında anlamlı bir ilişki saptanmadı $(p>0,05)$.

Sonuç: Ergenlerin yaş grubunda çevrimiçi oyun oynama sıklığının yüksek olduğu ve erkeklerde bağımlıığın daha yüksek olduğu saptandı. Ayrıca şiddet içerikli film seyredenlerin çevrimiçi oyun bağımlıığı ölçeği puan ortalaması daha yüksekti. Akran zorbalığı ve çevrimiçi oyun bağımlıığı arasında bir ilişki bulunmadı. Bu konuda yeni çalışmalara intiyaç olduğu düşünülmektedir.

Anahtar Sözcükler: Ergen, çevrimiçi oyun bağımlılı̆ı, akran zorbalığı.

\section{Abstract}

Aim: Computer game addiction is a growing health problem around the world. The majority of online games include violence, which creates other problems. In this study, we investigated the relationship between online game addiction and peer bullying among adolescents.

Materials and Methods: 400 adolescents between 12 and 18 who applied to the pediatric polyclinic for various reasons were the study sample. Three questionnaires about sociodemographic data, online game addiction, and peer bullying were applied.

Results: The mean age of the study group was 17 (12-18). The study group's online game addiction mean score was $52.9 \pm 18.2$, the peer bullying-victim mean score was $148.8 \pm 79.6$, and the peer bullying-bullying score was $150 \pm 83.1 .88 .4 \%$ of the adolescents reported that they played online games. The average game addiction score was $50 \pm 17.6$ and $56.4 \pm 18.5$ for females and males, which was statistically higher in males $(p=0.004)$. There was no significant relationship between online game addiction and peer bullying point average ( $p>0.05)$. Online game addiction score averages were found to be higher for war movies watchers $(p=0.001)$. There was no significant relationship between the mean score of the peer bullying and the type of film watched ( $p>0.05)$.

\footnotetext{
Yazışma Adresi: Zahide Yalaki

S. B. Ankara Eğitim ve Araştırma Hastanesi, Çocuk Sağlığı ve

Hastalıkları Kliniği, Ankara, Türkiye

E-mail: dr_zahide@yahoo.com

Makalenin Geliş Tarihi: 11.06.2018 Kabul Tarihi: 24.09.2018
} 
Conclusion: Male adolescents had a higher frequency of online gaming than females. The average score of the online gaming addiction was higher for violent movie viewers. There was no correlation between peer bullying and online game addiction. More studies are needed in this area.

Keywords: Adolescent, online game addiction, peer bullying.

\section{Giriş}

Oyun, çocukların sosyal ilişkilerini etkileyen, sosyal ve zihinsel becerilerinin gelişmesini sağlayan önemli bir araçtır. Bu sayede çocuklar, arkadaşları ile birlikte oynadıkları oyunlar sayesinde iletişim becerilerini geliştirip kendini ifade etme, arkadaşlık ilişkileri kurma gibi sosyal beceriler kazanırlar $(1,2)$. Eskiden oyun parklarında, sokaklarda arkadaşlarla beraber oyunlar oynanırken artık günümüzde evlerde veya internet kafelerde çocuklar bilgisayar başında sanal oyunlar oynamaktadır. Pek çok ailenin evinde bilgisayar ve internet, mobil telefonlar ve tablet bilgisayarlar bulunmaktadır.

Internet ve bilgisayar yaşamı kolaylaştırması, geliştirilen sistemler sayesinde kişiler arası iletişimi arttırması, bilgiye erişimi daha rahat hale getirmesi, film, müzik, video, oyun vb. ortamlara erişimi sağlayarak eğlenceli zaman yaşatması gibi nedenlerle günümüzün vazgeçilmezi haline gelmiştir (3). Bununla birlikte internet ve bilgisayar oyunları beraberinde birtakım sorunlar da getirmiştir. Sürekli internete bağlı olan ve bu sebeple yaşamlarında pek çok sorun oluşan bireylerin artması 'internet bağımlıı̆ı' kavramını ortaya çıkarmıştır. Sağlıklı internet kullanımı ise düşünsel, davranışsal, herhangi bir rahatsızlık duymaksızın, uygun bir zaman diliminde istenilen amaca ulaşmak için internet kullanımını ifade ederken, 'internet bağımlılığı' interneti sağlıklı olarak kullanmamak sonrası ortaya çıkan durum olarak tanımlanmaktadır (4).

Bilgisayar oyun bağımlılığının standart bir tanımı olmamakla birlikte bir davranış bağımlılığı olarak kabul edilmekte, bilgisayarın zararlı ve uzun süre kontrol dışı kullanımını ifade eden bir kavram olarak kullanılmaktadır (5-8).

Yapılan çalışmalarda çocukların bilgisayar oyunu oynama oranlarında önemli bir artış olduğu bildirilmektedir $(9,11)$. Bu artışla birlikte bağımlılık oranı da artmaktadır. Bilgisayar oyunları sadece bağımlılığa yol açmamakta, aynı zamanda çocuğun davranışlarını ve beyin fonksiyonlarını da olumsuz etkilemektedir. Oyun bağımlılığının uykusuz kalma, okula güçlükle gitme, aile-arkadaş programlarına güçlükle katılma, çeşitli görevlerinden veya katıldığı bir spor takımından ayrılma, sosyal ilişkilerde çatışmalar, depresyon, anksiyete, somatizasyon, öfke, saldırganlık, düşmanlık ve stres gibi olumsuz durumlara neden olduğu bildirilmektedir $(12,14)$. Zboralski ve ark. (15) aşırı bilgisayar ve internet kullanımının yüksek düzeyde saldırganlık ve anksiyete ile ilişkili olduğunu ortaya koymuşlardır. Ayrıca ergenin internette uzun, kontrolsüz bir biçimde zaman geçirmesi ve internetin gittikçe artan kullanım sıklığı ergenin akran ilişkilerini olumsuz etkilemektedir. İnternet nedeniyle iletişim becerileri azalan ergenin cesaret, girişkenlik, iletişim kurma gibi kişilik özellikleri olumsuz etkilenebilmekte ve gerçek arkadaşlık yerine internet arkadaşlığı veya yalnız kalmayı tercih edebilmektedir (16).

Şiddet her geçen gün toplumun her kesiminde giderek artış gösteren, bireylerin ve toplumun yaşamını olumsuz etkileyen bir sorun olmaktadır. Son yıllarda okullarda da şiddet her geçen gün artmaktadır $(17,18)$. Okullardaki şiddet sadece saldırganlık şeklinde değil akran zorbalığı şeklinde de karşımıza çıkmaktadır $(19,20)$.

Literatür incelendiğinde günümüzde gittikçe artan bilgisayar oyun bağımlılığı ile akran zorbalığı arasında bir ilişki varlığını araştıran çalışmaya rastlanmadı. Bu nedenle çalışmamızda ergen yaş grubunda çevrimiçi oyun bağımlılığının, günümüzde öğrenciler arasında yaşanan ve giderek artan akran zorbalığı ile ilişkisinin olup olmadığını araştırmak amaçlanmıştır.

\section{Gereç ve Yöntem}

Hastanemiz çocuk hastalıkları polikliniğine herhangi bir nedenle başvuran 12-18 yaş arası 400 ergen çalışmaya alındı. Ölçekleri getirmeyen 12 ve eksik dolduran sekiz olgu çalışma grubundan çıkarılarak toplam 380 olgu ile çalışma tamamlandı. Kronik fiziksel hastalığı olanlar, mental retardasyon tanısı olan hastalar çalışmaya alınmadı.

Olgulara sosyodemografik verileri sorgulayan 22 sorudan oluşan anket formu, çevrimiçi oyun bağımlılık ölçeği (ÇiOB) ve akran zorbalığı (ergen formu) verildi. 
Çevrimiçi oyun bağımlılığı ölçeği; aksaklıklar faktörü (9 soru), başarı faktörü (8 soru) ve ekonomik kazanç faktörü (4 soru) alt gruplarını değerlendiren 21 sorudan oluşmaktadır. Geçerlilik ve güvenirliği Kaya $A$. tarafından yapılan bu ölçekten ergenlerin alacağı minimum puan 21, maksimum puan 105 'tir (21).

Akran zorbalığı ölçeği; fiziksel (15 soru), sözel (7 soru), dışlama (6 soru), söylenti çıkarma (5 soru), eşyalara zarar verme (10 soru) ve cinsel zorbalık (10 soru) alt gruplarını değerlendiren 53 sorudan oluşmaktadır (19). Ölçekte zorbalık yapan 'zorba' ve zorbalığa uğrayan 'kurban' olarak tanımlanmaktadır. Geçerlilik ve güvenirliği Külcü $A$. Tarafından yapılan bu ölçekte alınabilecek minimum puan 53, maksimum puan 265 olmaktadır. Her iki ölçekte de alınan puan artııça oyun bağımlılığı ve akran zorbalığının arttığı şeklinde yorumlanmaktadır.

Çalışmaya katılan ailelerden, ergenlerden ve hastanemiz etik kurulundan 0036 numara ve 14.02.2018 tarih ile izin alındı.

Veriler SPSS 20.0 paket programında değerlendirildi. Sürekli ve kesikli sayısal değişkenlerin dağılımının normale yakın olup olmadığı Kolmogorov Smirnov testiyle araştırıldı; dağılımları normalden farklı olan değişkenlerin tanımlayıcı istatistikleri ortanca (en küçük - en büyük) şeklinde, dağılımları normal olanların ortalama \pm standart deviasyon şeklinde verildi. Kategorik değişkenler için tanımlayıcı istatistikler olgu sayısı ve "\%" biçiminde gösterildi. Gruplar arasında ortalama değerler yönünden farkın önemliliği Student's $\mathrm{t}$ testiyle, ortanca değerler yönünden farkın önemliliği ise Mann Whitney $U$ testi ile araştırıldı. Kategorik değişkenler Pearson'un Ki-Kare veya Fisher'in Kesin Sonuçlu Ki-Kare testiyle değerlendirildi. İki sürekli değişken arasındaki korelasyon Pearson Korelasyon testi ile değerlendirildi; $p<0,05$ için sonuçlar istatistiksel olarak anlamlı kabul edildi.

\section{Bulgular}

Çalışma grubunun yaş ortancası 17 yıl (12-18) ve \%63,7'i ( $n=242)$ kız idi. Ergenlerin cinsiyete göre yaş dağılımları benzer bulundu $(p=0,677)$. Ergenlerin \%89,5'i (n=340) okula gidiyordu. Ergenlerin \%97,4'ünün $(n=370)$ kendine ait telefonu, \%86,3'ünün $(n=328)$ kendine ait bilgisayarı vardı. Facebook üyeliği $\% 55$ 'inde $(n=209)$, instagram üyeliği \%83,7'inde $(n=318)$, twitter üyeliği ise $\% 30,5^{\prime}$ inde $(n=116)$ mevcuttu. Ergenlerden sadece \%11,8'inin $(n=45)$ herhangi bir sosyal medya üyeliği bulunmamakta idi; \%22'sinin $(n=77)$ ise üç sosyal medya üyeliği mevcuttu. Ergenlerin \%90,3'ünde $(n=343)$ internet bağlantısı evde bulunmaktaydı. Ergenlerin \%54,2'si $(n=206)$ komik, \%28,7'si ( $n=109)$ savaş ve \%17,1'i $(n=65)$ dram türü film seyretmekten hoşlanıyordu (Tablo-1).

Annelerin yaş ortancası 41,5 yıl (31-60), babaların yaş ortancası 45 yıl (34-76) idi. Annelerin \%2,1'i $(n=8)$ okur-yazar değil, \%37,1'i $(n=141)$ ilkokul, $\% 27,9$ 'u $(n=106)$ ortaokul ve \%32,9'u $(n=125)$ liseüniversite mezunu idi. Babaların ise $\% 1,5^{\prime} i(n=6)$ okur-yazar değil, \%24,5'i (n=93) ilkokul, \%29'u $(n=110)$ ortaokul ve $\% 45{ }^{\prime} i \quad(n=171)$ lise-üniversite mezunu idi. Ebeveynlerin \%97,9'unda $(n=372)$ cep telefonu vardı ve annelerin \%41,1'i $(n=156)$, babaların ise \%45'i $(n=171)$ telefon ile oyun oynuyordu.

Ergenlerin \%88,4'ü (n=336) çevrimiçi oyun oynadıklarını belirtti. Oyun oynayanların $\% 12,5^{\prime} \mathrm{i}$ $(n=42) \quad<1$ saat, \%26,2'si $(n=88)$ 2-3saat ve $\% 61,3$ 'ü $(n=206)>3$ saat bilgisayarda oyun oynadığını belirtmişti. Ergenlerin \%68,1'i ebeveynlerinin hangi oyunları oynadıklarını bilmediğini belirtti. Çalışma grubunun oynadıkları oyunlar hakkında ebeveynlerinin bilgi ve tutumları Tablo-2'de belirtilmiştir.

Çalışma grubunun çiOB puan ortalaması $52.9 \pm 18$,2 olarak saptandı. Kızlarda çiOB ölçeği puan ortalaması $50 \pm 17,6$, erkeklerde ise $56,4 \pm 18,5$ idi ve erkeklerde istatistiksel olarak daha yüksek bulundu $(p=0,004)$. Çevrimiçi oyun bağımlılığı ölçeği puan ortalaması ile okula gitme arasında anlamlı bir ilişki saptanmadı $(p=0,267)$. Savaş içeren film seyredenlerin ÇiOB ölçeği puan ortalaması $(58,3 \pm 20,4)$, komedi $(50,5 \pm 16,2)$ ve dram $(51,2 \pm 18,3)$ içeren film seyredenlerin puan ortalamasına göre daha yüksek bulundu $(p=0,001)$. Hem anne hem de baba eğitim düzeyi arttıkça ÇiOB puan ortalamasının artı̆ğı saptandı. Kendine ait bilgisayarı olanlar ile çíOB puan ortalaması, arasında anlamlı bir ilişki saptanmadı $(p=0,821)$. Bilgisayarda $>3$ saat oynayanların ÇíOB puan ortalaması, $<1$ saat ve 2-3 saat oynayanlara göre anlamlı olarak daha yüksekti $(p=0,001)$ (Tablo-3). 
Tablo-1. Çalışma grubunun sosyodemografik verileri $(n=380)$.

\begin{tabular}{|c|c|c|}
\hline & $\mathbf{N}$ & $\%$ \\
\hline \multicolumn{3}{|l|}{ Cinsiyet } \\
\hline $\mathrm{KIZ}$ & 242 & 63,7 \\
\hline Erkek & 138 & 36,3 \\
\hline \multicolumn{3}{|l|}{ Okula gidiyor mu? } \\
\hline Evet & 340 & 89,5 \\
\hline \multicolumn{3}{|l|}{ Anne eğitimi } \\
\hline Okur-yazar değil & 8 & 2,1 \\
\hline Okuryazar/Illkokul & 141 & 37,1 \\
\hline Ortaokul & 106 & 27,9 \\
\hline Lise-üniversite & 125 & 32,9 \\
\hline \multicolumn{3}{|l|}{ Baba eğitimi } \\
\hline Okur-yazar değil & 6 & 1,5 \\
\hline Okuryazar/ilkokul & 93 & 24,5 \\
\hline Ortaokul & 110 & 29 \\
\hline Lise-üniversite & 171 & 45 \\
\hline \multicolumn{3}{|c|}{ Kendine ait telefon var mı? } \\
\hline Evet & 370 & 97,4 \\
\hline \multicolumn{3}{|c|}{ Kendine ait bilgisayar var mı? } \\
\hline Evet & 328 & 86,3 \\
\hline \multicolumn{3}{|l|}{ Facebook üyeliği olma } \\
\hline Evet & 209 & 55 \\
\hline \multicolumn{3}{|c|}{ İnstagram üyeliği olma } \\
\hline Evet & 318 & 83,7 \\
\hline \multicolumn{3}{|l|}{ Twitter üyeliği olma } \\
\hline Evet & 116 & 30,5 \\
\hline \multicolumn{3}{|l|}{ Film türü } \\
\hline Komedi & 206 & 54,2 \\
\hline Savaş & 109 & 28,7 \\
\hline Dram & 65 & 17,1 \\
\hline \multicolumn{3}{|c|}{ Çevrimiçi oyun oynama } \\
\hline Evet & 336 & 88,4 \\
\hline
\end{tabular}

Tablo-2. Çalışma grubunun oynadıkları oyunlar hakkında ebeveynlerinin bilgi ve tutumları $(n=336)$.

\begin{tabular}{lcc}
\hline & $\mathbf{n}$ & $\%$ \\
\hline "Ailen hangi oyunları oynadığını bilir mi?” & 68,2 \\
Evet & 229 & 31,8 \\
Hayır & 107 & 36,9 \\
"Ailen oyunun şiddet içerip içermediğini bilir mi?” & & \\
Evet & 124 & \\
Hayır & 212 & 39,3 \\
"Ailen oyun süresine karışır mı?” & & 60,7 \\
Evet & 132 & 27,4 \\
Hayır & 204 & 66,6 \\
"Ailen hangi oyunları satın aldığını bilir mi?” & 92 & 224 \\
Evet & & \\
Hayır & & \\
\hline
\end{tabular}


Tablo-3. 'Çevrimiçi oyun bağımlılığı ölçeği' ve 'Akran zorbalığı ölçeklerinin' sosyodemografik verilerle karşılaştırılması ${ }^{*}(n=380)$.

\begin{tabular}{|c|c|c|c|}
\hline & $\begin{array}{l}\text { Çevrimiçi oyun } \\
\text { bağımlılığı ölçeği }\end{array}$ & Akran zorbalığı-kurban & Akran zorbalığı-zorba \\
\hline $\begin{array}{l}\text { Cinsiyet } \\
\text { Kız } \\
\text { Erkek } \\
p\end{array}$ & $\begin{array}{c}50,6 \pm 17,6 \\
56,4 \pm 18,5 \\
\mathbf{0 , 0 0 4}\end{array}$ & $\begin{array}{c}147,5 \pm 81,5 \\
151,0 \pm 76,3 \\
0,679\end{array}$ & $\begin{array}{c}148,5 \pm 86,6 \\
154,5 \pm 76,8 \\
0,505\end{array}$ \\
\hline $\begin{array}{l}\text { Oyun süresi } \\
<1 \text { saat } \\
2-3 \text { saat } \\
>3 \text { saat } \\
p\end{array}$ & $\begin{array}{c}49,3 \pm 17,9 \\
52,5 \pm 15,2 \\
64,0 \pm 18,6 \\
\mathbf{0 , 0 0 1}\end{array}$ & $\begin{array}{c}216 \pm 66,2 \\
138 \pm 75,7 \\
138,5 \pm 70,6 \\
\mathbf{0 , 0 0 1}\end{array}$ & $\begin{array}{c}223 \pm 62.9 \\
140.9 \pm 79,6 \\
140.4 \pm 70,9 \\
\mathbf{0 , 0 0 1}\end{array}$ \\
\hline $\begin{array}{l}\text { Kendine ait bilgisa } \\
\text { olma } \\
\text { Evet } \\
\text { Hayır } \\
\text { p }\end{array}$ & $\begin{array}{c}52,9 \pm 17,9 \\
52,3 \pm 19,9 \\
0,821\end{array}$ & $\begin{array}{c}148,8 \pm 78,9 \\
148,7 \pm 83,9 \\
0,994\end{array}$ & $\begin{array}{c}150,8 \pm 81,8 \\
149,4 \pm 91,4 \\
0,909\end{array}$ \\
\hline $\begin{array}{l}\text { Anne eğitimi } \\
\text { Okur-yazar değil } \\
\text { Okuryazar/lilkokul } \\
\text { Ortaokul } \\
\text { Lise-üniversite } \\
\text { p }\end{array}$ & $\begin{array}{c}48,7 \pm 14,4 \\
50,5 \pm 18,3 \\
49,5 \pm 17,1 \\
57,4 \pm 18,06 \\
\mathbf{0 , 0 0 2}\end{array}$ & $\begin{array}{c}140,4 \pm 70,9 \\
140,9 \pm 79,6 \\
150 \pm 62,9 \\
145,6 \pm 64,7 \\
0,960\end{array}$ & $\begin{array}{c}154,2 \pm 64,4 \\
149,9 \pm 62,5 \\
151,6 \pm 79,2 \\
145,7 \pm 67,3 \\
0,472\end{array}$ \\
\hline $\begin{array}{l}\text { Baba eğitimi } \\
\text { Okur-yazar değil } \\
\text { Okuryazar/ilkokul } \\
\text { Ortaokul } \\
\text { Lise-üniversite } \\
\text { p }\end{array}$ & $\begin{array}{c}46,8 \pm 13,4 \\
49,3 \pm 18,07 \\
50,6 \pm 16,5 \\
56,0 \pm 18,7 \\
\mathbf{0 , 0 2 4}\end{array}$ & $\begin{array}{c}142,9 \pm 68,3 \\
146,7 \pm 81,2 \\
153,4 \pm 74,4 \\
149,8 \pm 64,7 \\
0,909\end{array}$ & $\begin{array}{c}157,8 \pm 64,5 \\
152,7 \pm 72,8 \\
145,9 \pm 69,4 \\
148,8 \pm 74,6 \\
0,505\end{array}$ \\
\hline $\begin{array}{l}\text { Film türü } \\
\text { Komedi } \\
\text { Savaş } \\
\text { Dram } \\
\text { p }\end{array}$ & $\begin{array}{c}50,5 \pm 16,2 \\
58,3 \pm 20,4 \\
51,2 \pm 18,3 \\
\mathbf{0 , 0 0 1}\end{array}$ & $\begin{array}{c}144,8 \pm 69,5 \\
148,7 \pm 74,7 \\
151,5 \pm 81,6 \\
0,969\end{array}$ & $\begin{array}{c}151,4 \pm 68,7 \\
154,7 \pm 83,5 \\
149,7 \pm 79,4 \\
0,498\end{array}$ \\
\hline $\begin{array}{l}\text { Okula devam etme } \\
\text { durumu } \\
\text { Evet } \\
\text { Hayır } \\
\text { p }\end{array}$ & $\begin{array}{c}51,7 \pm 16,8 \\
54,4 \pm 13,7 \\
0,267\end{array}$ & $\begin{array}{c}151,4 \pm 72,5 \\
148,9 \pm 64,5 \\
0,965\end{array}$ & $\begin{array}{c}149,7 \pm 63,7 \\
146,8 \pm 77,8 \\
0,944\end{array}$ \\
\hline
\end{tabular}

*: İstatistiksel değerlendirmelerde Student's t testiyle kullanıldı.

Tablo-4. 'Çevrimiçi oyun bağımlılığı ölçeği' ile 'Akran zorbalığı' arasındaki ilişki*.

\begin{tabular}{lll}
\hline & Akran zorbalığı-kurban & Akran zorbalığı-zorba \\
\hline Çevrimiçi oyun bağımlılığı ölçeği & $\mathrm{p}=0,727$ & $\mathrm{p}=0,500$ \\
& $\mathrm{r}=0,020$ & $\mathrm{r}=0,038$ \\
\hline
\end{tabular}

**: İstatistiksel değerlendirmede Pearson korelasyon testi kullanıldı. 
Akran zorbalığı-kurban ölçeği puan ortalaması $148,8 \pm 79,6$ ve akran zorbalığı-zorba ölçeği puan ortalaması 150 $\pm 83,1$ idi. Akran zorbalığı ölçek puan ortalaması ile cinsiyet arasında anlamlı fark saptanmadı. Akran zorbalığı ölçek puan ortalaması ile okula gitme arasında anlamlı bir ilişki saptanmadı $(p>0,05)$. Akran zorbalığı ölçeği puan ortalaması ile seyredilen film türü, ebeveyn eğitim düzeyi ve kendine ait bilgisayarı olma durumu arasında anlamlı bir ilişki saptanmadı $(p>0,05)$. Akran zorbalığı-zorba ve akran zorbalığı- kurban ölçeğinin puan ortalaması $>3$ saat oyun oynayanlarda, $<1$ saat oynayanlara göre anlamlı olarak daha yüksek saptandı $(p=0,001)$ (Tablo-3).

Çevrimiçi oyun bağımlılığı ölçeği puan ortalaması ile akran zorbalığı- kurban ölçeği puan ortalaması ve akran zorbalığı- zorba ölçeği puan ortalaması arasındaki korelasyon değerlendirildiğinde anlamlı ilişki saptanmadı (sırası ile, $p=0,727 \quad r=0,020$; $\mathrm{p}=0,500 \mathrm{r}=0,038)$ (Tablo-4).

\section{Tartışma}

Bilgisayar ve internet pek çok alanda yaşamı kolaylaştırırken oyun ve eğlence aracı olarak da giderek yaygınlaşan bir ilgi alanı haline gelmiştir. Şehirleşmenin giderek artması, oyun alanlarının yetersizliği gibi nedenlerle çocukların sokakta oynayacakları oyunların yerini dijital oyunlar almıştır. Her yaşta kullanıcısı olan oyunlara gençler daha çok ilgi göstermektedir ve oyun oynayarak geçirdikleri süre giderek artmaktadır $(1,3)$.

Çalışmalarda 10-18 yaş arası erkek ergenlerde aşırı oyun oynama ve bağımlıı̆̆ın kızlara göre daha sık olduğu ve bilgisayar oyun bağımlıı̆̆ının depresyon, saldırganlık ve şiddet eğilimine neden olduğu bildirilmektedir (1-3). Yıldız ve ark.'nın (2) ilkokul çocuklarında yaptıkları çalışmada erkeklerde bilgisayar bağımlıı̆̆ının kızlara göre daha çok olduğu ve oyundan vazgeçememe, engellendiğinde rahatsız olma durumunun da erkeklerde daha çok olduğu bildirilmiştir. Çalışmamızda da benzer şekilde erkeklerde çiOB ortalaması daha yüksek saptandı.

Yapılan çalışmalarda anne ve babanın eğitim düzeyi arttıkça bilgisayar oyun bağımlılık düzeyinin de artığı bildirilmiştir $(1,6)$. Çalışmamızda da buna benzer şekilde anne ve babanın eğitim düzeyi arttıkça bilgisayara ulaşımın kolay olması, bilgisayar bağımlıı̆ı̆ın artmasına neden olabileceğini düşündürmüştür. Ayrıca anne eğitim düzeyinin artması ile annenin evin dışında daha çok vakit geçirmesi, çalışması nedeni ile evde olduğu saatlerde ev işleri ile ilgilenirken çocukları fazla kontrol edemediğini bu nedenle çocukların daha çok bilgisayar başında vakit geçirdiği düşünülmüştür. Anne-babanın eğitim düzeyi ile akran zorbalığı ölçekleri arasında herhangi bir ilişki saptanmadı. Yapılan çalışmalarda da annebabanın eğitim düzeyi ile akran zorbalığı ölçekleri arasında herhangi bir ilişki saptanmamıştır $(19,22)$.

Çalışmamızda şiddet içerikli film seyredenlerin ÇiOB puanı daha yüksek saptandı. Ergenlerin öğrendikleri şiddeti oyun bağımlılığına yansıttığı düşünüldü. Ancak akran zorbalığı ve çiOB arasında ilişki bulunmadı. Bu durumun Çi̇B oynamayan grubumuzun az olmasından kaynaklanabileceği düşünüldü.

Oyun süresi de oyun bağımlılığında önemli olmaktadır. Öncel ve ark.'nın (23) ilköğretim öğrencilerinde yaptığı çalışmada, kızlarda oyun bağımlıığının daha fazla olduğu ayrıca çalışmaya katılan tüm çocukların $\% 67,6$ 'ı <1 saat, \%28,2'i 1-3 saat, \%1,4'ü 3-5 saat, \%2,8'i >5 saat bilgisayar oyunu oynadığını bildirmiştir. Kelleci ve ark.'nın (24) yaptıkları çalışmada da; kızların $\% 70,2$ 'i, erkeklerin \%60,2'i 1-2 st/gün, kızların \%25,2'i, erkeklerin \%23,1'i 3-4 st/gün, kızların \%4,5'i, erkeklerin \%16,8'i >5 st/gün internet kullandığı bildirilmiştir. Çalışmamızda da benzer şekilde ergenlerin \%73,2'i >3 saat oyun oynadığını belirtti ve bu grupta doğal olarak ÇiOB puanını daha yüksek olduğu saptandı.

Onay ve ark.'nın (11) yaptığı çalışmada kendine ait kişisel bilgisayarı olan çocukların oyun bağımlılığının, olmayanlara göre daha fazla olduğu bildirilmiştir. Horzum'un (1) yaptığı çalışmada ise kişisel bilgisayarı olma durumu ile oyun bağımlılığı arasında ilişki bulunmamıştır. Bizim çalışmamızda da Horzum'un çalışmasına benzer şekilde kişisel bilgisayarın olup olmaması ile çiOB puanı arasında ilişki saptanmadı.

Dünya'da ve ülkemizde okullarda akranlar arasında yaşanan şiddet olaylarına yoğun olarak rastlanmaktadır. Akran zorbalığı üzerine yapılan son çalışmalarda, akran zorbalığının birkaç farklı tipinin olduğu saptanmıştır. "Fiziksel ve Sözel Zorbalık", en çok bilinen zorbalık türüdür. İtme, tekmeleme, vurma, üzerine bir şey veya eşya atma gibi davranışlar fiziksel zorbalığa örnek davranışlardır (25). Zorbalığın öğrenciler için ciddi 
bir travma olduğu, etkilerinin okul dönemi ile sınırlı kalmayıp, yaşam boyu sürdüğü ve toplum sağlığını da olumsuz etkilediği kabul edilmektedir (26). Zorba davranışları, çocukların son zamanlarda bağımlıık haline gelen bilgisayar oyunlarından öğrenmiş olma hipotezi ile yaptığımız çalışmada, ergenlerin ÇiOB ortalaması ile akran zorbalığızorba ve akran zorbalığı-kurban arasında ilişki saptanmadı.

Çalışmaya katılan ergenlere herhangi bir psikiyatrik hastalıklarının olup olmadığı, psikiyatrik tedavi alıp almadığı sorulmaması ve zekâ kapasitelerinin değerlendirilmemesi çalışmanın kısıtılıklarıdır. Bu durumların varığının sonuçları etkileyebileceği düşünülmüştür.

Sonuç olarak; ergen yaş grubunda çevrimiçi oyun oynama sıklığının yüksek olduğu ve erkeklerde bağımlılığın daha yüksek olduğu saptandı. Akran zorbalığı ve çevrimiçi oyun bağımlılığı arasında bir ilişki bulunmadı. Bu durumun çevrimiçi oyun oynamayan grubumuzun az olmasından kaynaklı olabileceği düşünüldü. Bu konuda yeni çalışmalara intiyaç olduğu düşünülmektedir.

\section{Kaynaklar}

1. Horzum MB. İlköğretim öğrencilerinin bilgisayar oyunu bağımlılık düzeylerinin çeşitli değişkenlere göre incelenmesi. Eğitim ve Bilim 2011; 36 (159): 56-68.

2. Yıldız E, Tüfekçi F.G, Aksu E. Çocuklarda bilgisayar oyunu bağımııı̆ı ile sosyal anksiyete arasındaki ilişki ve etkileyen faktörler. Turkiye Klinikleri J Public Health Nurs-Special Topics 2016; 2 (1): 54-60.

3. Irmak A.Y, Erdogan S. Ergen ve genç erişkinlerde dijital oyun bağımlıı̆ı̆: güncel bir bakış. Türk Psikiyatri Dergisi 2016; 27 (2): 128-37.

4. Davis, RA. A cognitive-behavioral model of pathological internet use. Computers in Human Behavior 2001; 17 (2): 187-95.

5. Peltoniemi, T. Net addiction in Finland. First Prevnet Conference of Telematics in Addiction Prevention, Atina, Yunanistan 2002.

6. Şahin $C$, Tuğrul VM. İlköğretim öğrencilerinin bilgisayar oyunu bağımlılık düzeylerinin incelenmesi. J World of Turks 2012; 4 (3): 115-30.

7. Gentile DA. Pathological video game use among youth 8 to 18: A national study. Psychol Sci 2009; 20 (5): 594 602.

8. Desai RA, Krishnan-Sarin S, Cavallo D, Potenza MN. Video-gaming among high school students: Health correlates, gender differences, and problem atic gaming. Pediatrics 2010; 126 (6): 1414-24

9. Kuss DJ, Griffiths MD. Online gaming addiction in children and adolescents: A review of empirical research. $J$ Behav Addict 2012; 1 (1): 3-22.

10. Harris $\mathrm{J}$. The effects of computer games on young children: A review of the research. J Amer Academy of Child Adolescent 2001; 72 (22): 1-30.

11. Onay PD, Tüfekçi $A$, Çağıltay K. Türkiye'deki öğrencilerin bilgisayar oyunu oynama alışkanlıkları ve oyun tercihleri: ODTU ve Gazi Üniversitesi öğrencileri arası karşılaştırmalı bir çalışma, Bilişim Teknolojileri Işığında Eğitim Konferansı, Ankara. 2005.

12. Lemos IL, Abreu CN, Sougey EB. Internet and video game addictions: a cognitive behavioral approach. Revista de Psiquiatria Clínica 2014; 41 (3): 82-8.

13. Yaman E, Sönmez Z. Ergenlerin siber zorbalık eğilimleri. Online J Technology Addiction and Cyberbullying, 2015; 2 (1): 18-31.

14. Doğan FÖ. Video games and children: violence in video games. New/Yeni Symposium Journal 2006; 44 (4): 161 4.

15. Zboralski AC, Orzechowska DE, Talarowska DE, et al. The prevalence of computer and internet addiction among pupils. Postepy Hig Med Dosw (online) 2009; 63: 8-12.

16. Yücel N, Gürsoy F. Ergenlerin akran ilişkileri ile yalnızlık düzeylerinde internet kullanımının etkisi. (Ed. Kalkan M, Kaygusuz C). İnternet Bağımlıı̆ı̆ı Sorunlar ve Çözümler. Anı Yayıncılık: Ankara. 2013.

17. Lımbos M. Casteel C. Schools and neighborhoods: Organizational and environmental factors associated with crime in secondary schools. Journal of School Health 2008; 78 (10): 539-44.

18. Çelen HN. Ergenlik ve genç yetişkinlik. Papatya yayıncııı eğitim. 1. Basım. İstanbul, 2007; 117-43. 
19. Külcü DP. Çocuklarda akran zorbalığı ve benlik saygısının incelenmesi. Yüksek lisans tezi. Mersin, 2015.

20. Ayas T, Pişkin M. Akran zorbalığı belirleme ölçeği ergen formu. Akademik Bakış Dergisi 2015; 50: 316-24.

21. Kaya $A B$. Çevrimiçi oyun bağımlıı̆̆ı ölçeğinin geliştirilmesi: Geçerlik ve güvenirlik çalışması. Yüksek lisans tezi. Tokat, 2013.

22. Çetinkaya S, Nur N, Ayvaz A, Özdemir D, Kavakcı Ö. Sosyoekonomik durumu farklı üç ilköğretim okulu öğrencilerinde akran zorbalığının depresyon ve benlik saygısı düzeyiyle ilişkisi. Anadolu Psikiyatri Dergisi 2009; 10 (2): $151-8$.

23. Öncel $M$, Tekin A. Ortaokul öğrencilerinin bilgisayar oyun bağımlıı̆ı ve yalnızlık durumlarının incelenmesi. J Educational Science Institute 2015; 2 (4): 7-17.

24. Kelleci M, Güler N, Sezer H, Gölbaşı Z. Lise öğrencilerinde internet kullanma süresinin cinsiyet ve psikiyatrik belirtiler ile ilişkisi. TAF Preventive Medicine Bulletin 2009; 8 (3): 223-30.

25. Özkan Y, Çiftçi EG. Düşük sosyo-ekonomik düzeydeki ilköğretim okullarında akran zorbalığı. Elementary Education Online. 2010; 9 (2): 576-86.

26. Kepenekci YK, Çınkır S. Bullying among Turkish high school students. Child Abuse Negl 2006; 30 (2): 193-204. 